\title{
Functional interplay between glutathione and hydrogen sulfide in regulation of thiol cascade during arsenate tolerance of common bean (Phaseolus vulgaris L.) genotypes
}

\author{
Dibyendu Talukdar
}

Received: 29 December 2014 / Accepted: 21 February 2015/Published online: 4 March 2015

(c) The Author(s) 2015. This article is published with open access at Springerlink.com

\begin{abstract}
Changes in expressions of up- and downstream thiol cascade were studied in leaves of Phaseolus vulgaris L. cv. VL-63 and its mutant, pvsodl (deficient in superoxide dismutase activity) under $50 \mu \mathrm{M}$ sodium arsenate (As), As + L-buthionine-sulfoximine (BSO) and $\mathrm{As}+\mathrm{BSO}+$ Sodium hydrosulfide (NaHS)-treatments for 10 days. Main objective was to investigate the functional relationship between hydrogen sulfide $\left(\mathrm{H}_{2} \mathrm{~S}\right)$ and glutathione $(\mathrm{GSH})$ in regulation of sulfate transporters and cysteine metabolisms as up-stream thiol components and GSH, phytochelatins (PCs) and antioxidant defense response as downstream cascade under As-exposure. As treatment alone initiated coordinated inductions of sulfate transport, biosynthesis of cysteine, GSH, and PCs, and GSH-mediated antioxidant defense in the pvsodl mutant. At As + BSO, GSH synthesis was blocked, resulting in significantly low GSH redox pool and steep decline in GSH-dependent antioxidant capacity of both the genotypes. However, unlike VL-63, cysteine-degradation pathway was induced in pvsodl mutant, resulting in significant accumulation of endogenous $\mathrm{H}_{2} \mathrm{~S}$. The $\mathrm{H}_{2} \mathrm{~S}$-surge in the pvsodl mutant stimulated ascorbate-dependent antioxidant defense and catalases and regulated O-acetylserine (thiol)lyase activity, preventing overaccumulation of $\mathrm{H}_{2} \mathrm{O}_{2}$ and free cysteine, respectively. No As-induced oxidative stress symptom was observed in the mutant. This trend was maintained at As $+\mathrm{BSO}+\mathrm{NaHS}$ treatment, also. In contrast, failure to induce entire cascade from sulfate transport to downstream antioxidant defense led to onset of As-induced oxidative damage in VL-63 plant. Results
\end{abstract}

D. Talukdar $(\bowtie)$

Department of Botany, R.P.M. College (University of Calcutta), Uttarpara, West Bengal 712258, India

e-mail: dibyendutalukdar9@gmail.com revealed dual roles of $\mathrm{H}_{2} \mathrm{~S}$ as (a) stimulator of GSH-independent antioxidant defense and (b) regulator of cysteine homeostasis through its metabolic diversion during Asexposure and blockage of GSH biosynthesis.

Keywords Arsenate - BSO - Thiol cascade - Sulfide · Ascorbate $\cdot$ Phaseolus vulgaris

\section{Introduction}

Arsenic (As) is a ubiquitous toxic and carcinogenic metalloid. Food crops such as rice, pulses and vegetables grown in As-contaminated soil can accumulate high levels of As (Bhattacharya et al. 2010). Common bean (Phaseolus vulgaris L.) is a widely grown antioxidant-rich food legume (Liao et al. 2012) but the crop is sensitive to As (Stoeva et al. 2005; Talukdar 2013). Being grown in aerobic fields, legumes are usually exposed to arsenate (AsV) form of As which either directly or through conversion to highly toxic arsenite (AsIII) adversely affects plant growth by generating excess reactive oxygen species (ROS) and consequent oxidative damage to membrane structure and function (Gupta et al. 2008).

Sulfur (S) is an essential nutrient for plant growth and development, and is generally taken up by plants in the form of sulfate through dedicated sulfate transporters (Sultr) (Kopriva et al. 2012). Sulfate is then reduced to sulfide and ultimately incorporated into the amino acid skeleton of O-acetylserine (OAS) by the O-acetylserine (thiol) lyase (OAS-TL) (Hell and Wirtz 2011; Takahashi et al. 2011). Cysteine (Cys) is the first committed molecule in plant metabolism that contains both $\mathrm{S}$ and nitrogen, and, thus, its metabolic regulation is of utmost importance for the synthesis of a number of essential metabolites in plant 
pathways (Kopriva et al. 2012). Conglomerations of thiol transport as well as assimilation and thiol-dependent antioxidant defense comprise thiol cascade and thiol-ligand glutathione (GSH) play central roles in this cascade (Finnegan and Chen 2012). Growing evidences suggest that decreased activity of Cys-synthesizing machinery ultimately compromises GSH and phytochelatin (PC) synthesis and effectiveness of antioxidant defense in As-sensitive plants (Srivastava et al. 2009). GSH synthesis is catalyzed by $\gamma$-glutamylcysteine synthetase $(\gamma$-ECS) in a rate-limiting way (Noctor et al. 2012). Besides formation of PCs, GSH is an integral part of ascorbate (AsA)-GSH antioxidant cycle in which dehydroascorbate reductase (DHAR), ascorbate peroxidase (APX) and glutathione reductase (GR) along with catalases (CAT) and GSH-Stransferase (GST) outside the cycle play pivotal roles in redox homeostasis (Noctor et al. 2012). While sulfur uptake/transport and Cys/GSH synthesis are the key components at the up-stream, GSH-dependent antioxidant defense constitute the downstream thiol cascade during plants' response to stress.

Knowledge regarding metabolic channeling of Cys into different routes to regulate plant growth and development has recently been widened with the discovery of role of Cys-generated hydrogen sulfide $\left(\mathrm{H}_{2} \mathrm{~S}\right)$ as a prominent signaling molecule in plants (Calderwood and Kopriva 2014). Recent research has confirmed that most of the endogenously synthesized $\mathrm{H}_{2} \mathrm{~S}$ occurred through the desulfuration of L-Cys and D-Cys by L-cysteine desulfhydrase (LCD) and D-cysteine desulfhydrase (DCD), respectively (Álvarez et al. 2010). $\mathrm{H}_{2} \mathrm{~S}$ participates in diverse physiological activities to promote plant growth processes and abiotic stress tolerance (Chen et al. 2011; Calderwood and Kopriva 2014). However, it is still not clear whether these effects are from $\mathrm{H}_{2} \mathrm{~S}$ alone or these are mediated by downstream thiol-antioxidant metabolites like GSH.

Substantial progress has been made in revealing central roles of GSH during As-detoxification. However, it is not known whether Cys degradation and endogenous $\mathrm{H}_{2} \mathrm{~S}$ has any roles in mitigating As-toxicity in crop plants. Recently, an EMS-induced bean mutant pvsodl deficient in SOD activity was found tolerant to As (V) stress. Primary investigation revealed possible interplay between GSH and Cys-degraded $\mathrm{H}_{2} \mathrm{~S}$ in mitigating As-stress in the mutant. Main objectives of this study were therefore to explore (1) the response of sulfate transport and its assimilation into Cys, (2) the roles of GSH and response of antioxidant defense enzymes, and (3) involvement of Cys metabolisms other than GSH in leaves of common bean genotype subjected to As (V) treatment. The study hypothesized that functional interplay exists between two Cys-metabolites, the GSH and $\mathrm{H}_{2} \mathrm{~S}$, during As-induced oxidative stress in leaves of common bean.

\section{Materials and methods}

Plant material, growth conditions and treatment protocol

Fresh seeds of common bean (Phaseolus vulgaris L.) cultivar VL-63 and one pvsodl mutant exhibiting low superoxide dismutase (SOD) activity (25\% of wild type) (Talukdar and Talukdar 2013) were surface sterilized with $\mathrm{NaOCl}(0.1 \%, \mathrm{w} / \mathrm{v})$ and continuously washed under running tap water followed by distilled water. Seeds were allowed to germinate in the dark in two separate sets on moistened filter paper at $25{ }^{\circ} \mathrm{C}$. Germinated seedlings were randomly placed in polythene pots $(10 \mathrm{~cm}$ diameter and $12 \mathrm{~cm}$ high, 10 plants pots $^{-1}$ ) containing $250 \mathrm{ml}$ of Hoagland's No 2 nutrient media, and were allowed to grow for 10 days. Seedlings of both the genotypes were then subjected to (a) $50 \mu \mathrm{M}$ of As (sodium arsenate, MW $312.01 \mathrm{~g} \mathrm{~mol}^{-1}$; technical grade, purity $98.5 \%$, SigmaAldrich, Bangalore, India) treatment, (b) As $+1 \mathrm{mM}$ BSO (L-buthionine-sulfoximine, Sigma-Aldrich, Bangalore, India), (c) As $+1 \mathrm{mM} \mathrm{BSO}+100 \mu \mathrm{M}$ NaHS (Sodium hydrosulfide, SRL, Mumbai, India) and were allowed to grow for another 10 days. BSO was used as specific inhibitor of GSH biosynthesis, while NaHS was the exogenous $\mathrm{H}_{2} \mathrm{~S}$ donor. Pilot experiments indicated significant effect of arsenate, BSO and NaHS at these concentrations on plant biomass (Talukdar 2013; Talukdar and Talukdar 2013) and thus, were selected for the present study. Untreated plants were used as control; cultivar as mother control (MC) and mutant line as mutant control (MuC). The experiment was carried out in a completely randomized block design in an environmentally controlled growing chamber under a 14-h photoperiod, $28 / 18 \quad\left( \pm 2{ }^{\circ} \mathrm{C}\right)$, relative humidity of $70 \pm 2 \%$, and a photon flux density of $150 \mu \mathrm{mol} \mathrm{m} \mathrm{m}^{-2} \mathrm{~s}^{-1}$. Nutrient solution was refreshed thrice per week, and all experiments were conducted thrice with four replicates. After 10 days, As-exposed seedlings were harvested along with control, carefully washed with distilled water, blotted gently, and were oven-dried at $60{ }^{\circ} \mathrm{C}$ till constant weight. Root and shoot dry weights were measured and fresh leaves were used for metabolic and molecular analysis.

\section{Determination of As content and endogenous $\mathrm{H}_{2} \mathrm{~S}$}

As concentration in dried root and shoot samples was measured by digestion methods $\left(\mathrm{HNO}_{3}-\mathrm{HClO}_{4}\right.$ mixture at $3: 1, \mathrm{v} / \mathrm{v})$ using flow injection-hydride generation atomic absorption spectrophotometer (Perkin-Elmer, FIA-HAAS Analyst 400) and keeping Standard Reference Materials of tomato leaves (item number 1573a, from National Institute of Standards and Technology, USA) for part of the quality assurance/quality control protocol, as detailed earlier 
(Talukdar 2013). The translocation factor (TF) is the ratio of the level of As in shoots upon roots. Endogenous $\mathrm{H}_{2} \mathrm{~S}$ was determined by the formation of methylene blue from dimethyl-p phenylenediamine in $\mathrm{H}_{2} \mathrm{SO}_{4}$ following Sekiya et al. (1982) and Chen et al. (2011).

Measurement of glutathione, ascorbate, Cys and assay of thiol-metabolizing enzymes

Reduced and oxidized form of ascorbate and glutathione were measured following the methods of Law et al. (1983) and Griffith (1980), respectively. For enzyme assay, plant tissue was homogenized in buffers specific for each enzyme under chilled conditions. The homogenate was squeezed through four layers of cheese cloth and centrifuged at $12,000 \times g$ for $15 \mathrm{~min}$ at $4{ }^{\circ} \mathrm{C}$. The protein content of the supernatant was measured following Bradford (1976) using BSA as standard. The OAS-TL (EC 2.5.1.47) activity was assayed by measuring the production of L-Cys (Saito et al. 1994). Cys content was measured spectrophotometrically (Perkin-Elmer, Lambda 35, Mumbai, India) at $560 \mathrm{~nm}$ following Gaitonde (1967). Assay of $\gamma$-ECS (EC 6.3.2.2), PC synthase (PCS; EC 2.3.2.15) and LCD (EC 4.4.1.1) was done by following Seelig and Meister (1984), Howden et al. (1995), and Bloem et al. (2004), respectively. DCD (EC 4.4.1.15) activity was determined in the same way, but D-Cys was used instead of L-Cys (Riemenschneider et al. 2005).

Assay of antioxidant enzymes and glycolate oxidase (GO)

Leaf tissue of $250 \mathrm{mg}$ was homogenized in $1 \mathrm{ml}$ of $50 \mathrm{mM}$ K-phosphate buffer $(\mathrm{pH} 7.8)$ containing $1 \mathrm{mM}$ EDTA, $1 \mathrm{mM}$ DTT, and $2 \%$ (w/v) polyvinyl pyrrolidone using a chilled mortar and pestle kept in an ice bath. The homogenate was centrifuged at $15,000 \times g$ at $4{ }^{\circ} \mathrm{C}$ for $20 \mathrm{~min}$. Clear supernatant was used for enzyme assays. Soluble protein content was determined using BSA as a standard (Bradford 1976). SOD (EC 1.15.1.1) activity was determined by nitro blue tetrazolium (NBT) photochemical assay (Beyer and Fridovich 1987) and expressed as unit per minute per milligram protein. One unit of SOD was equal to that amount causing a $50 \%$ decrease of SOD-inhibited NBT reduction. APX (EC 1.11.1.11) activity (nmol AsA oxidized $\min ^{-1} \mathrm{mg}^{-1}$ protein) was assayed following Nakano and Asada (1981) with $\mathrm{H}_{2} \mathrm{O}_{2}$-dependent oxidation of AsA followed by a decrease in the absorbance at $290 \mathrm{~nm}$ $\left(\varepsilon=2.8 \mathrm{mM}^{-1} \mathrm{~cm}^{-1}\right)$. DHAR (EC 1.8.5.1) and GR (EC 1.6.4.2) activity was measured following the protocol of Nakano and Asada (1981) and Carlberg and Mannervik (1985), respectively. CAT (EC 1.11.1.6) extraction was performed in a $50-\mathrm{mM}$ Tris- $\mathrm{HCl}$ buffer. The enzyme activity was assayed by measuring the reduction of $\mathrm{H}_{2} \mathrm{O}_{2}$ at $240 \mathrm{~nm}\left(\varepsilon=39.4 \mathrm{mM}^{-1} \mathrm{~cm}^{-1}\right)$ and $25^{\circ} \mathrm{C}$, as detailed earlier (Talukdar 2013). GSTs (EC 2.5.1.18) specific activity was assayed following $\mathrm{Li}$ et al. (1995). GO (EC 1.1.3.15) activity was assayed by the formation of a glyoxylate-phenylhydrazone complex at $324 \mathrm{~nm}$ (Baker and Tolbert 1966) and was expressed as $\mu$ mol glyoxylate $\min ^{-1} \mathrm{mg}^{-1}$ protein.

Estimation of foliar $\mathrm{H}_{2} \mathrm{O}_{2}$ content, lipid peroxidation and electrolyte leakage (EL) \%

Leaf $\mathrm{H}_{2} \mathrm{O}_{2}$ content and membrane lipid peroxidation rate were determined following Wang et al. (2007) and by measuring the malondialdehyde (MDA) equivalents (Hodges et al. 1999), respectively. Electrolyte leakage (EL \%) was measured according to Dionisio-Sese and Tobita (1998).

Relative gene expression analysis through quantitative RT-PCR

Total RNA isolation and first-strand cDNA synthesis were done following manufacturer's (Chromous Biotech, Bangalore, India) instructions, as detailed earlier (Talukdar and Talukdar 2014a). The quality of total RNA samples was determined spectrophotometrically (Systonic, Kolkata, India) from $A 260 / 280$ ratio as well as by $1 \%$ agarose gel electrophoresis, and $600 \mathrm{ng}$ of mRNA was used for cDNA synthesis. Quantitative RT-PCR of first-strand cDNA was run on ABI Step-One (Applied Biosystems, Foster City, CA, USA) Real-Time PCR machine. Amplification was done in a total reaction volume of $50 \mu \mathrm{l}$, containing template (first-strand cDNA) $2.0 \mu \mathrm{l}$, forward and reverse primer $2.0 \mu \mathrm{l}$ each with $50 \mathrm{nM} \mu l^{-1}$ concentration, $2 \times$ PCR SYBR green ready mixture (Fast Q-PCR Master Mix, Chromous Biotech, India, cat no. QCR 05/QCR 06), $25.0 \mu \mathrm{l}$, and DEPC water $19.0 \mu \mathrm{l}$. Primers for selected genes were constructed by Primer Express ${ }^{\text {TM }}$ V. 3.0 software (Applied Biosystems, USA) with the search of available sequence databases (http://www.phytozome.net/ commonbean.php; http://plantgrn.noble.org/PvGEA/) and reports on Phaseolus vulgaris (Liao et al. 2012; Talukdar and Talukdar 2013) and were presented in Table 1. The qRT-PCR cycling stages comprised of initial denaturation step at $94{ }^{\circ} \mathrm{C}$ ( $\left.3 \mathrm{~min}\right)$, followed by 35 cycles of $94{ }^{\circ} \mathrm{C}(5 \mathrm{~s})$, $62{ }^{\circ} \mathrm{C}(10 \mathrm{~s}), 72{ }^{\circ} \mathrm{C}(10 \mathrm{~s})$ and a final extension stage at $72{ }^{\circ} \mathrm{C}(2 \mathrm{~min})$. A melting curve analysis was performed after every PCR reaction to confirm the accuracy of each amplified product. Samples for qRT-PCR were run in four biological replicates with each biological replicate contained the average of three technical replicates. RT-PCR reaction mixtures were loaded onto $2 \%$ agarose gels in 
Table 1 Oligonucleotide primer sequence $\left(5^{\prime} \rightarrow 3^{\prime}\right)$ used in qRT-PCR reactions

\begin{tabular}{|c|c|c|}
\hline Candidate genes & Forward primers & Reverse primers \\
\hline PvSultr $1 ; 1$ & CGTTCGTCAGAGAGTGCTAGCTCC & ATGTGTTTATGTATATGAATAGAC \\
\hline PvSultr $1 ; 2$ & ATCGGTGGACATGTATCCGATGA & CATGTGTAGCTTGCCTATCACCAA \\
\hline PvSultr $2 ; 1$ & GATCATAGTTCAAACTTCCACACA & CCGTAAATTCATCACATGCAATAA \\
\hline PvSultr $2 ; 2$ & CTTGGATCCATGGCATAGAGCTTC & GTATCCATCAACACAACTCGGGGA \\
\hline$O A S-T L A$ & CGGCACAAGATTCAAGGGATAA & ATCATGGCTTCCGCTTCTTTG \\
\hline$O A S-T L B$ & AAACAGCGACGTCGTTTTGCAGCT & CTCTTCTCGAATCGACTGGAAAAG \\
\hline$\gamma-E C S$ & AGCTGTGTCCCACCGAGTG & AAGAGTGAGCGGAGGAGGGT \\
\hline$P C S$ & CCTAATGGAATCTGATGTGCCTT & CTTCTTTGACAGTCGACGAGCCTT \\
\hline$P v L C D$ & GATGCAATGTATTTGTCTCTTTTTC & TTTCTTTTTATAATCTTTTGCTCCC \\
\hline$P v D C D$ & AGAACAGTTCTCTCTTTTTGTCGA & GGACAGTCCACCTTAGAGGCTAGA \\
\hline$G O$ & TAGTTCTCGTGCTGTTGCCGATA & AAGGATATGCTGTTACATTACGTT \\
\hline $\mathrm{Cu} / \mathrm{ZnSODI}$ & GGCTGTATGTCAACTGGACCTCATTTCA & TGTCAACAATGTTGATAGCAGCGG \\
\hline $\mathrm{Cu} / \mathrm{ZnSODII}$ & GGATATATGGCATCTGTAACTCATATGC & GCATAAGAATGCTGATAGACAGGG \\
\hline$M n S O D$ & AGTCAAGTTGCAGAGTGCAATCAAGTTC & CAAAGTGATTGTCAATAGCCCAAC \\
\hline FeSOD & AACAAGCAAATAGCCGGAACAGAACAC & AGAAATCGTGATTCCAGACCTGA \\
\hline$A P X I$ & CACTTGGCCCTGGACCGTTGTTGTT & CCAGAACCGTCCTTGTAAGTTGC \\
\hline$A P X I I$ & CAGAGGAGAGTGAAGGCAAAGC & GTCAGTCAAGCTGCATACGATA \\
\hline$A P X I I I$ & GCGACTTCTCCAGCCGATCAAATC & AGGACATTGGTCAGGTCCAG \\
\hline DHAR & CCTAACAAACCCGAATGGTA & ACGGGCACCTTTCCTTCAG \\
\hline$G R I$ & GAAATTGCTAGTCTGTATGCGTCA & AGCAAACTCCAAGGCACAATGT \\
\hline GRII & GCACTGCTCTTCACGTAGACCGCT & AATGGCTGTGGGTGATGTCCGAA \\
\hline$C A T$ & TACTCAGAGGCACCGTCTTG & CTCCTCATCTCGGTGCATAA \\
\hline Ubiquitin & GCTTCGTGGTGGAATGCAGAT & TCGCACCTTGGCAGACTACAA \\
\hline
\end{tabular}

TAE buffer. A 100-bp DNA ladder was run on every gel. The mRNA levels were normalized against a common bean ubiquitin as the housekeeping gene, and the relative (fold change to control value) expression of target genes was calculated as $2^{-\Delta \Delta \mathrm{Ct}}$ (Livak and Schmittgen 2001).

Statistical analysis

Data are mean \pm standard error (SE) of at least four replicates. Simple $t$ test was performed to assess significant differences ( $P_{\text {two tailed }}$ ) between control and treated values. Variance analysis was performed on all experimental data, and statistical significance $(P<0.05)$ of means was determined by Duncan's multiple range test using SPSS software (SPS Inc., USA v. 10.0).

\section{Results}

Changes in plant dry weight and As accumulation

Both shoot and root dry weight in VL-63 seedlings reduced significantly $(P \leq 0.0001)$ in comparison to $\mathrm{MC}$ at $50 \mu \mathrm{M}$ As, further reduced at As $(50 \mu \mathrm{M})+1 \mathrm{mM} \mathrm{BSO}$, and did not change significantly $(P=0.483)$ at As $+1 \mathrm{mM}$
$\mathrm{BSO}+100 \mu \mathrm{M}$ NaHS in relation to As $+\mathrm{BSO}$. Dry weight of pvsodl mutant compared to $\mathrm{MuC}$ did not change significantly in any of the three treatment protocols (Fig. 1a). At $50 \mu \mathrm{M}$, As accumulation was markedly higher in roots than that of shoots $(P \leq 0.0001)$ in VL-63 (Shoot/root $\mathrm{TF}<1$ ) while completely opposite scenario was observed in the pvsodl mutants (Fig. 1b). As concentration in shoot and root of the VL-63 turned reverse (Shoot/root TF ratio $>1 ; P \leq 0.0001$ ) to the above under $\mathrm{As}+\mathrm{BSO}$ and As $+\mathrm{BSO}+\mathrm{NaHS}$. Significantly $(P \leq 0.0001)$ higher As level than the VL-63 was estimated in shoots of pvsodl mutant $(\mathrm{TF}>3.0)$ throughout the treatment regimes (Fig. 1b).

Foliar GSH and AsA content and their redox states

Total GSH and AsA content and their corresponding redox states increased significantly $(P=0.025-0.010)$ over MuC in leaves of the As-treated pvsodl mutant. GSH and AsA level reduced while their oxidized forms increased substantially in VL-63 exposed to As + BSO and As + $\mathrm{BSO}+\mathrm{NaHS}$ (Table 2). In pvsodl mutant, GSH redox declined nearly fivefold but AsA redox increased significantly over $\mathrm{MuC}$ in the latter two protocols (Table 2). Change was non-significant in rest of the cases. 

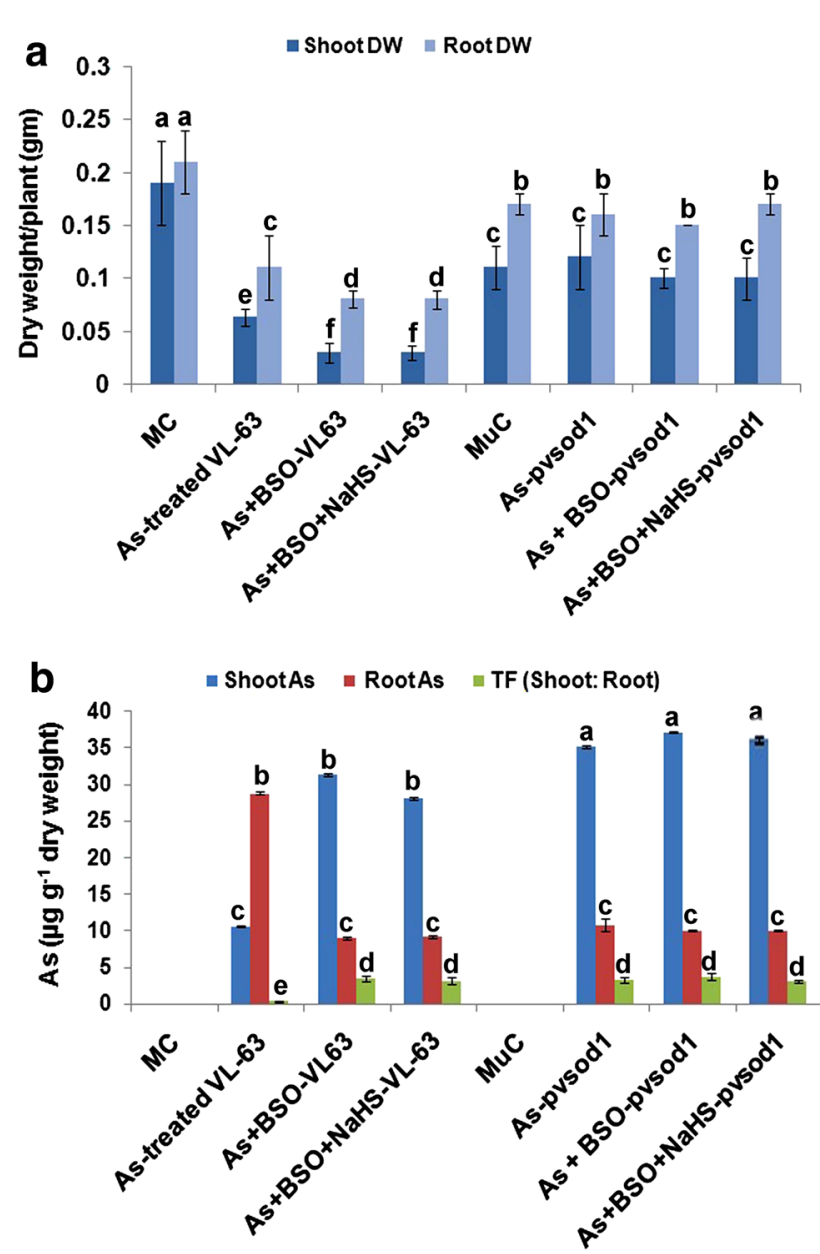

Fig. 1 Changes in a shoot and root dry weight (g) and b as accumulation and transfer (TF) ratio in Phaseolus vulgaris L. mother genotype VL-63 and its mutant pvsod1 in control (MC mother control, $\mathrm{MuC}$ mutant control, $0 \mu \mathrm{M}$ of As), As (Sodium arsenate, $50 \mu \mathrm{M}$ )treated, As $+1 \mathrm{mM}$ BSO, and As $+1 \mathrm{mM} \mathrm{BSO}+100 \mu \mathrm{M}$ NaHS treatments. Data are mean $\pm \mathrm{SE}$ of four replicates of three independent experiments. Means followed by the different lowercase letters were significantly different at $P<0.05$ using ANOVA followed by Duncan's multiple range tests

Cys content, endogenous $\mathrm{H}_{2} \mathrm{~S}$ level and response of thiol-metabolizing enzymes

Compared to MuC, foliar Cys content in pvsodl mutant did not change significantly in any of the treatment regimes (Table 2). Cys level was close to MC value in As-treated VL-63 but doubled when BSO was co-applied with As (Table 2). The $\mathrm{H}_{2} \mathrm{~S}$ level showed significant increase (2.5fold) over $\mathrm{MuC}$ in $\mathrm{As}+\mathrm{BSO}-$ treated pvsodl mutant and became 4.2-fold higher in the mutant at $\mathrm{As}+\mathrm{BSO}+$ NaHS (Table 2). Compared to MC, change in $\mathrm{H}_{2} \mathrm{~S}$ level was not significant in VL-63 when As was co-imposed with BSO and also with NaHS (Table 2).

Activities of OAS-TL, $\gamma$-ECS, PCS increased significantly $(P=0.018-0.011)$ over $\mathrm{MuC}$ in As-treated mutant (Table 3). At As + BSO, $\gamma$-ECS activity was not detectable while PCS level reduced significantly $(P \leq 0.0001)$ in both the genotypes. The OAS-TL level in the mutant was close to $\mathrm{MuC}$, but LCD and DCD activity increased by about 2.5- to 2.7-fold over $\mathrm{MuC}$ in the mutant. Activities of all five enzymes followed trend similar to As + BSO in both the genotypes subjected to As + BSO + NaHS treatment. Change was not significant in rest of the cases (Table 3).

Response of antioxidant enzymes and photorespiratory ROS production

Foliar SOD activity was constitutively low in pvsodl mutant but increased significantly over MC in VL-63 exposed to three treatment protocols. Barring CAT activity which assayed low, activities of APX, DHAR, CAT and GR increased significantly $(P \leq 0.010)$ in the mutant exposed to As only (Table 3). At As + BSO and As + BSO + NaHS, activities of APX and DHAR were reduced by about twofold to fourfold in VL-63 but along with CAT, increased significantly $(P \leq 0.002)$ in the mutant (Table 3$)$. GST activity increased over MuC by about fourfold in the As-treated mutant but reduced significantly below MuC level when BSO was co-applied in the medium. In Astreated VL-63, GST level reduced by about twofold of MC value and further declined in As + BSO and As + B$\mathrm{SO}+\mathrm{NaHS}$ medium (Table 3$)$. Significant $(P=0.0017)$ increase was observed in activity of GO, a major source of photorespiratory $\mathrm{H}_{2} \mathrm{O}_{2}$ production, in both VL-63 and $p v$ sodl mutant exposed to $\mathrm{As}+\mathrm{BSO}$ and at $\mathrm{NaH}-$ $\mathrm{S}+\mathrm{As}+\mathrm{BSO}$ (Table 3). Enzyme activity did not change significantly in rest of the cases.

Changes in foliar $\mathrm{H}_{2} \mathrm{O}_{2}$ content, lipid peroxidation and electrolyte leakage \%

Foliar $\mathrm{H}_{2} \mathrm{O}_{2}$ content, MDA and EL \% were significantly higher $(P \leq 0.001)$ in VL-63 than $\mathrm{MC}$ at $50 \mu \mathrm{M}$ As and further increased at As + BSO and maintained the level at As + BSO + NaHS (Table 4). Compared to MuC, changes were non-significant $(P=0.151)$ in pvsodl mutant throughout the treatment regimes (Table 4).

Gene expression pattern of selected genes

At $50 \mu \mathrm{M}$ As, PvSultr2;1 and PvSultr 2;2 sulfate transporters were up-regulated by about 2.2 -fold in pvsodl mutant while PvSultr 1;1 and PvSultr 1;2 changed nonsignificantly $(P=0.351)$ in both the genotypes (Fig. 2a, b). In As-treated pvsodl mutant, $O A S$-TL $A$ and $O A S-T L B$ were induced by about 1.8- to 2-fold, while $\gamma$-ECS and PCS were up-regulated over $\mathrm{MuC}$ by about twofold 
Table 2 Foliar GSH and GSSG (nmol g ${ }^{-1} \mathrm{FW}$ ), GSH redox [GSH/ $(\mathrm{GSH}+\mathrm{GSSG})]$, AsA and DHA (nmolg $\left.{ }^{-1} \mathrm{FW}\right)$, AsA redox [AsA/ $\left(\right.$ AsA + DHA) , Cysteine (Cys, nmol g $\left.{ }^{-1} \mathrm{FW}\right)$ and $\mathrm{H}_{2} \mathrm{~S}\left(\mu \mathrm{mol} \mathrm{g} \mathrm{g}^{-1}\right.$
FW) in mother genotype (Phaseolus vulgaris L.) VL-63 and the pvsodl mutant in $50 \mu \mathrm{M}$ As (sodium arsenate), As $+1 \mathrm{mM}$ BSO and As $+\mathrm{BSO}+100 \mu \mathrm{M}$ NaHS for 10 days treatment period

\begin{tabular}{|c|c|c|c|c|c|c|c|c|}
\hline \multirow[t]{2}{*}{ Traits } & \multirow[t]{2}{*}{ MC (VL-63) } & \multirow[t]{2}{*}{$\mathrm{MuC}(p v \operatorname{sod} 1)$} & \multicolumn{2}{|l|}{ As-treated } & \multicolumn{2}{|l|}{$\mathrm{As}+\mathrm{BSO}$} & \multicolumn{2}{|c|}{$\mathrm{As}+\mathrm{BSO}+\mathrm{NaHS}$} \\
\hline & & & VL-63 & pvsodl & VL-63 & pvsodl & VL-63 & pvsodl \\
\hline $\mathrm{SH}$ & $161.3 \pm 3.8 b$ & $130.5=$ & $157.3 \pm 3.5 b$ & $220.8 \pm 4.3 \mathrm{a}$ & $76.5 \pm$ & 59.7 & $86.5 \pm 4.7 \mathrm{~d}$ & 53.7 \\
\hline GSSG & $18.8 \pm 1.3 \mathrm{c}$ & $11.1 \pm 0.91 \mathrm{c}$ & $19.7 \pm 1.4 \mathrm{c}$ & $0.1 \pm 1.2 b$ & $101.1 \pm 5.1 \mathrm{a}$ & $104.3 \pm 4.7 \mathrm{a}$ & $90.1 \pm 5.1 \mathrm{a}$ & $109.3 \pm 4.7 \mathrm{a}$ \\
\hline GSH redox & $0.901 \pm 0.07 \mathrm{a}$ & $0.922 \pm 0.07 \mathrm{a}$ & $0.890 \pm 0.08 \mathrm{a}$ & $0.880 \pm 0.11 \mathrm{a}$ & $0.431 \pm 0.07 b$ & $0.364 \pm 0.03 \mathrm{c}$ & $0.487 \pm 0.05 b$ & $0.330 \pm 0.03 c$ \\
\hline AsA & $800.8 \pm 7.1 \mathrm{a}$ & $690.8 \pm 6$ & $793.8=$ & $779.1=$ & $332.9=$ & 840.7 & 335.8 & $3.1 \mathrm{a}$ \\
\hline HA & 101. & 104.5 & b & 107.0 & $3 \pm 4$ & 10 & a & $3.4 \mathrm{~b}$ \\
\hline AsA & $0.888 \pm$ & 0.861 & $9 \pm 0.0$ & 0.8 & $8 \pm 0.06 b$ & 0.8 & $=0.02 \mathrm{~b}$ & 0.890 \\
\hline ysteine & $7.28 \pm 0.49 b$ & $6.19 \pm 0.43 c$ & $7.31 \pm 0.51 b$ & $6.28 \pm 0.46 c$ & $57.63 \pm 0.67 \mathrm{a}$ & $6.24 \pm 0.48 c$ & $53.20 \pm 0.61 \mathrm{a}$ & $6.27 \pm 0.40 \mathrm{c}$ \\
\hline $\mathrm{H}_{2} \mathrm{~S}$ & $0.063 \pm 0.01 \mathrm{c}$ & $0.059 \pm 0.009 \mathrm{c}$ & $0.065 \pm 0.01 \mathrm{c}$ & $0.061 \pm 0.01 \mathrm{c}$ & $0.059 \pm 0.01 \mathrm{c}$ & $0.148 \pm 0.04 b$ & $0.061 \pm 0.01 \mathrm{c}$ & $0.248 \pm 0.07 \mathrm{a}$ \\
\hline
\end{tabular}

Data are mean \pm standard error of four replicates. Means followed by different lowercase letters indicate significant differences for a particular trait at $P<0.05$ by ANOVA followed by Duncan's Multiple Range Tests

Table 3 Activity of foliar OAS-TL (nmol Cys $\mathrm{min}^{-1} \mathrm{mg}^{-1}$ protein), $\gamma$-ECS (nmol $\gamma$-EC $\mathrm{min}^{-1} \mathrm{mg}^{-1}$ protein), PCS (nmol GSH eq $\min ^{-1} \mathrm{mg}^{-1}$ protein), LCD (nmol $\mathrm{H}_{2} \mathrm{~S} \mathrm{~min}^{-1} \mathrm{mg}^{-1}$ protein), DCD (nmol $\mathrm{H}_{2} \mathrm{~S} \mathrm{~min}^{-1} \mathrm{mg}^{-1}$ protein), and activities of SOD ( $\mathrm{U} \mathrm{mg}^{-1}$ protein), APX ( $\mu$ mol AsA oxi $\mathrm{min}^{-1} \mathrm{mg}^{-1}$ protein), DHAR ( $\mu$ mol AsA formed $\mathrm{min}^{-1} \mathrm{mg}^{-1}$ protein), GR (nmol NADPH oxi $\min ^{-1} \mathrm{mg}^{-1}$ proten), GST (Units $\mathrm{mg}^{-1}$ protein), CAT (nmol $\mathrm{H}_{2} \mathrm{O}_{2}$ $\mathrm{min}^{-1} \mathrm{mg}^{-1}$ protein) and GO ( $\mu$ mol glyoxylate $\mathrm{mg}^{-1}$ protein $\mathrm{min}^{-1}$ ) in mother genotype (Phaseolus vulgaris L.) VL-63 and pvsod1 mutant exposed to $50 \mu \mathrm{M}$ As (sodium arsenate), As $+1 \mathrm{mM} \mathrm{BSO}$ and As $+\mathrm{BSO}+100 \mu \mathrm{M}$ NaHS for 10 days treatment period

\begin{tabular}{|c|c|c|c|c|c|c|c|c|}
\hline \multirow[t]{2}{*}{ Traits } & \multirow[t]{2}{*}{ MC (VL-63) } & \multirow[t]{2}{*}{$\mathrm{MuC}(p v \operatorname{sod} 1)$} & \multicolumn{2}{|l|}{ As-treated } & \multicolumn{2}{|l|}{$\mathrm{As}+\mathrm{BSO}$} & \multicolumn{2}{|c|}{$\mathrm{As}+\mathrm{BSO}+\mathrm{NaHS}$} \\
\hline & & & VL-63 & Pvsodl & VL-63 & Pvsodl & VL-63 & pvsodl \\
\hline AS-TL & 15.2 & 14.4 & $\mathrm{~b}$ & $\mathrm{a}$ & $\mathrm{b}$ & $\mathrm{b}$ & 16.3 & 13 \\
\hline$\gamma$-ECS & $0.42 \pm 0.09 b$ & $0.47 \pm 0.09 b$ & $0.44 \pm 0.09 \mathrm{~b}$ & $0.82 \pm 0.32 \mathrm{a}$ & $0.00 \pm 0.00 \mathrm{c}$ & $0.00 \pm 0.00 \mathrm{c}$ & $0.00 \pm 0.00 \mathrm{c}$ & $0.00 \mathrm{c}$ \\
\hline $\mathrm{CS}$ & $0.81 \pm 0.07 \mathrm{c}$ & $0.93 \pm 0.07 b$ & $0.79 \pm 0.05 \mathrm{c}$ & $1.49 \pm 0.34 \mathrm{a}$ & $0.09 \pm 0.01 \mathrm{~d}$ & $0.13 \pm 0.02 \mathrm{~d}$ & $0.09 \pm 0.02 \mathrm{~d}$ & $0.05 \mathrm{~d}$ \\
\hline LCD & $21.41 \pm 0.58 b$ & $19.41 \pm 0.58 \mathrm{~b}$ & $20.94 \pm$ & $17.88 \pm 0.67 b$ & $21.14 \pm 0.49 b$ & $44.49 \pm 0.67 a$ & $20.41 \pm$ & 43.51 \\
\hline $\mathrm{CD}$ & $18.08 \pm 0.51 b$ & $16.10 \pm 0.51 b$ & $19.02 \pm$ & $17.30 \pm 0.59 b$ & $20 \pm$ & $8+12-1$ & $.53 \mathrm{~b}$ & $0.59 \mathrm{a}$ \\
\hline OD & 4 & 1 & 12 & $14.3 \pm 2.3 \mathrm{c}$ & $\mathrm{a}$ & $15.0 \pm 2.2 \mathrm{c}$ & $5 a$ & $2.4 \mathrm{c}$ \\
\hline APX & $90.6 \pm 4.3 \mathrm{c}$ & $103.7 \pm 4.2 b$ & $.2 \pm 4.8 \mathrm{c}$ & -7 & $.1 \pm 3.9 \mathrm{~d}$ & 1 & $5.4 \pm 4.0 \mathrm{~d}$ & $181.7 \pm$ \\
\hline HAR & $0.59 \pm 0.07 b$ & $0.50 \pm 0.11 b$ & $61 \pm 0.08 b$ & 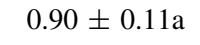 & $30 \pm 0.03 c$ & $93 \pm 0.23 \mathrm{a}$ & $33 \pm 2.3 \mathrm{c}$ & $0.90 \pm 0.24 \mathrm{a}$ \\
\hline $\mathrm{GR}$ & $41.6 \pm 2.2 b$ & $48.9 \pm 3.6 b$ & $42.3 \pm 2.8 b$ & $88.9 \pm 3.6 \mathrm{a}$ & $43.0 \pm 2.7 b$ & $46.9 \pm 4.6 b$ & $42.5 \pm 2.5 b$ & $48.9 \pm 4.9 \mathrm{~b}$ \\
\hline GST & $0.15 \pm 0.04 \mathrm{c}$ & $0.26 \pm 0.09 b$ & $0.10 \pm 0.04 \mathrm{c}$ & $1.03 \pm 0.08 \mathrm{a}$ & $0.05 \pm 0.00 \mathrm{~d}$ & $0.11 \pm 0.04 \mathrm{c}$ & $0.06 \pm 0.01 \mathrm{~d}$ & $0.13 \pm 0.04 \mathrm{c}$ \\
\hline CAT & $51.4 \pm 5.7 b$ & $47.4 \pm 6.2 b$ & $47.7 \pm 4.3 b$ & $31.4 \pm 6.2 \mathrm{c}$ & $49.4 \pm 5.0 \mathrm{~b}$ & $69.3 \pm 6.0 \mathrm{a}$ & $49.8 \pm 4.4 b$ & $70.1 \pm 6.1 \mathrm{a}$ \\
\hline $\mathrm{iO}$ & $0.81 \pm 0.03 b$ & $0.78 \pm 0.03 b$ & $0.83 \pm 0.04 b$ & $0.78 \pm 0.03 b$ & $1.67 \pm 0.09 a$ & $1.83 \pm 0.09 \mathrm{a}$ & $1.77 \pm 0.09 \mathrm{a}$ & $1.78 \pm 0.03$ \\
\hline
\end{tabular}

Data are mean \pm standard error of four replicates. Means followed by different lowercase letters indicate significant differences for a particular trait at $P<0.05$ by ANOVA followed by Duncan's Multiple Range Tests

(Fig. 2a, b). LCD, DCD and GO transcripts were as per control level in pvsodl mutant. Transcripts of $A P X I, A P X$ II, APX III, DHAR, GRI and II, and GST I and II were significantly $(P=0.003)$ up-regulated in the mutant but CAT repressed (Figs. 2a-c, 3a, b). Except $M n S O D$ and $\mathrm{Cu} / \mathrm{Zn}$ SODI which was induced, transcripts other SOD isoforms were not detectable in As-treated mutant (Fig. 3a, b). Barring significant up-regulation of $\mathrm{Cu} / \mathrm{Zn} S O D I$ and $I I$, other changes were not significant $(P=0.56)$ in VL-63 under As treatment alone.
At As + BSO, PvSultr 2;1, PvSultr 2;2, and OAS-TLA isoforms were up-regulated by about 2.8-, 2.5- and 2.9fold, respectively, while $O A S-T L B$ was down-regulated in the mutant. Transcripts of $L C D$ and $D C D$ were induced by nearly threefold in pvsodl mutant whereas GO transcript was elevated in both the genotypes by about 2.3-fold (Fig. 2a, b). Expressions of $\gamma$-ECS transcript could not be detected while PCS expression was down-regulated in both the genotypes (Fig. 2a, b). Among antioxidant defense components, expressions of SOD transcripts particularly 
Table 4 Foliar $\mathrm{H}_{2} \mathrm{O}_{2}\left(\mu \mathrm{mol} \mathrm{g}{ }^{-1} \mathrm{FW}\right)$, malondealdehyde (MDA, nmol g ${ }^{-1} \mathrm{FW}$ ) and electrolyte leakage (EL \%) in mother control genotype VL63 and pvsodl mutant in $50 \mu \mathrm{M}$ As (sodium arsenate), As $+1 \mathrm{mM}$ BSO and As $+\mathrm{BSO}+100 \mu \mathrm{M}$ NaHS for 10 days treatment period

\begin{tabular}{|c|c|c|c|c|c|c|c|c|}
\hline \multirow[t]{2}{*}{ Traits } & \multirow[t]{2}{*}{ MC (VL-63) } & \multirow[t]{2}{*}{$\mathrm{MuC}(p v \operatorname{sod} 1)$} & \multicolumn{2}{|l|}{ As-treated } & \multicolumn{2}{|l|}{$\mathrm{As}+\mathrm{BSO}$} & \multicolumn{2}{|c|}{$\mathrm{As}+\mathrm{BSO}+\mathrm{NaHS}$} \\
\hline & & & VL-63 & Pvsodl & VL-63 & Pvsodl & VL-63 & pvsodl \\
\hline $\mathrm{H}_{2} \mathrm{O}_{2}$ & $4.4 \pm 0.7 b$ & $4.7 \pm 0.8 b$ & $22.3 \pm 1.0 \mathrm{a}$ & $4.9 \pm 0.8 b$ & $18.8 \pm 1.1 \mathrm{a}$ & $5.1 \pm 0.8 b$ & $18.9 \pm 0.9 \mathrm{a}$ & $3.9 \pm 0.8 b$ \\
\hline MDA & $4.1 \pm 0.7 \mathrm{~b}$ & $5.2 \pm 0.9 \mathrm{~b}$ & $18.7 \pm 1.0 \mathrm{a}$ & $4.3 \pm 0.2 b$ & $16.9 \pm 1.0 \mathrm{a}$ & $4.9 \pm 0.7 b$ & $21.6 \pm 1.1 \mathrm{a}$ & $4.1 \pm 0.2 b$ \\
\hline EL \% & $3.3 \pm 0.5 b$ & $3.4 \pm 0.6 b$ & $19.1 \pm 1.2 \mathrm{a}$ & $4.1 \pm 0.3 b$ & $20.8 \pm 1.2 \mathrm{a}$ & $5.5 \pm 0.8 \mathrm{a}$ & $20.3 \pm 1.2 \mathrm{a}$ & $4.4 \pm 0.5 b$ \\
\hline
\end{tabular}

Data are mean \pm standard error of four replicates. Means followed by different lowercase letters indicate significant differences for a particular trait at $P<0.05$ by ANOVA followed by Duncan's Multiple Range Tests

Fig. 2 Transcript analysis of four sulfate transporters, OASTL, $\gamma$-ECS, PCS, DCD, LCD, and GSTs isoforms in leaves (leaflets + petioles) of VL-63 and pvsodl mutant of common bean, under control $(0 \mu \mathrm{M}$ of As), As (Sodium arsenate, $50 \mu \mathrm{M})$-treated, As $+1 \mathrm{mM}$ $\mathrm{BSO}$, and As $+1 \mathrm{mM}$ $\mathrm{BSO}+100 \mu \mathrm{M}$ NaHS treatments by a qRT-PCR, followed by $2 \%$ agarose gel electrophoresis with ubiquitin used for cDNA normalization and $\mathbf{b}, \mathbf{c}$ their relative expression levels. Data are mean \pm SE of three biological replicates with average of three technical replicates/biological replicate. Asterisk denotes the significant changes (up- or downregulation) in relation to control (set as 1 ) at $P<0.05$. Lane 1 mother control, 2 As-treated VL-63, 3 As + BSO-treated VL-63, 4 As + BSO + NaHStreated VL-63, 5 mutant control, 6 As-treated mutant, 7 As + BSO-treated mutant, 8 $\mathrm{As}+\mathrm{BSO}+\mathrm{NaHS}$-treated mutant; M-100-bp DNA marker (M) (arrow $200 \mathrm{bp}$ )
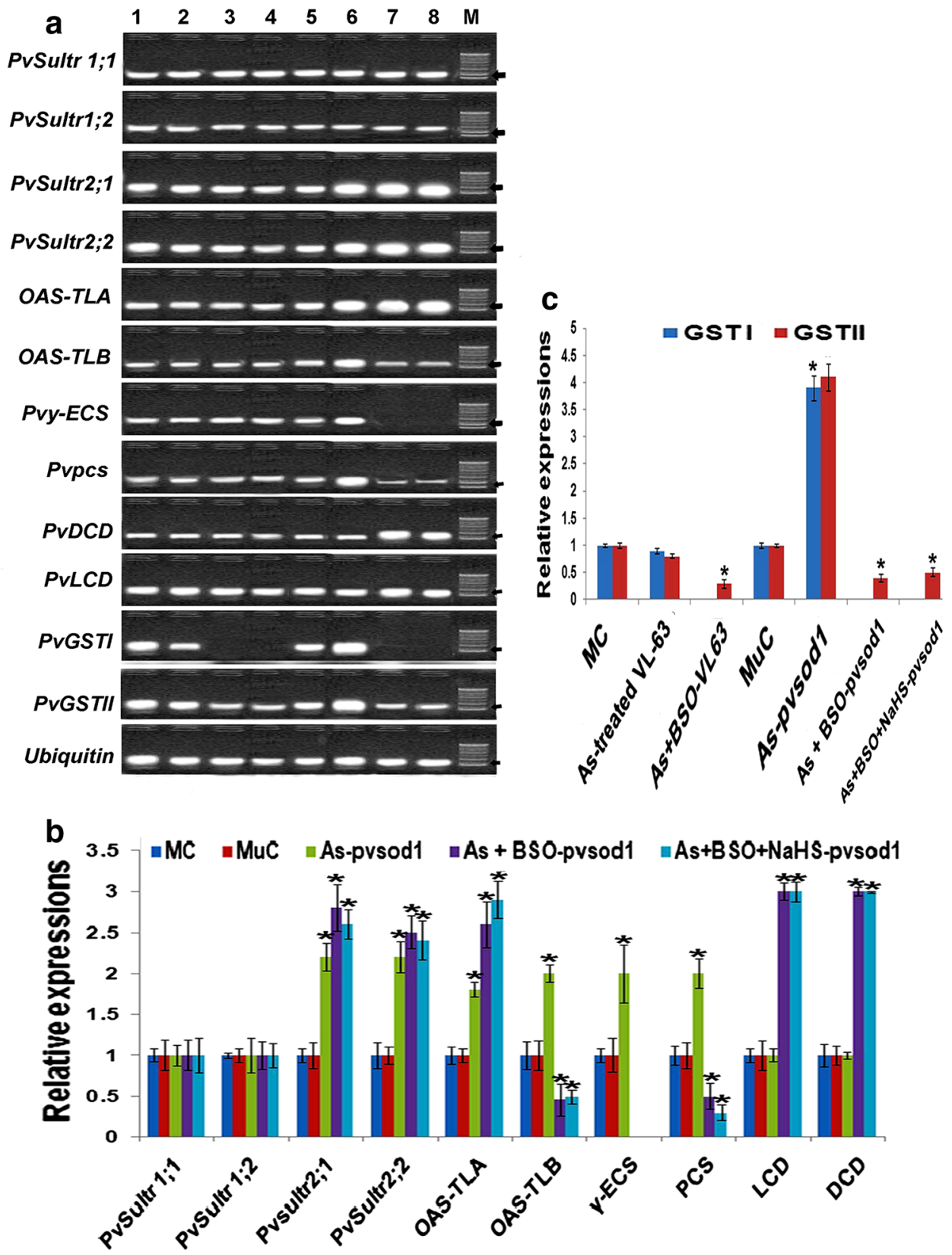


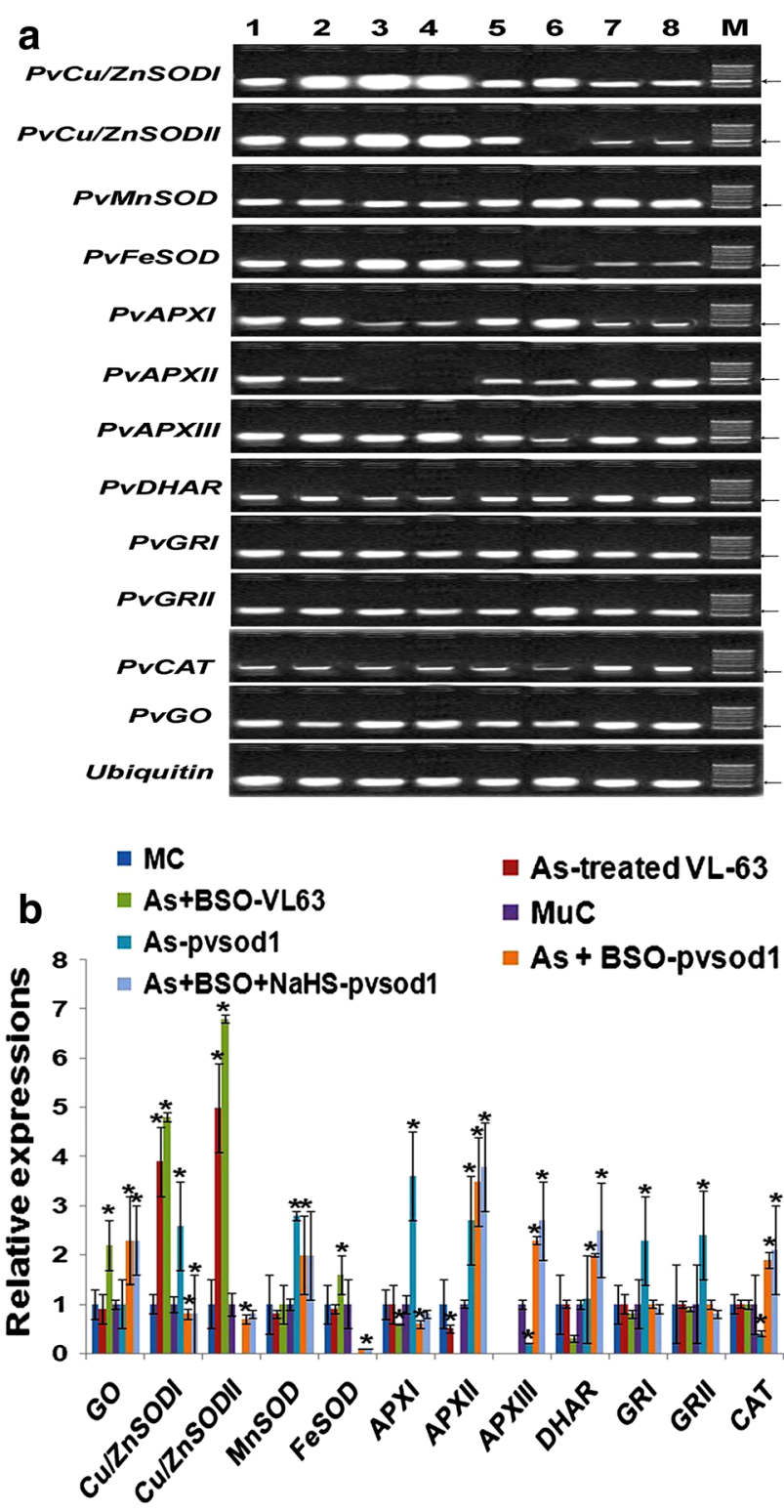

Fig. 3 Transcript analysis of $\mathrm{Cu} / \mathrm{Zn}$ SOD, Mn SOD, Fe SOD, APX, DHAR, GR, CAT, and GO isoforms in leaves (leaflets + petioles) of VL-63 and pvsodl mutant of common bean, under control $(0 \mu \mathrm{M}$ of As), As (Sodium arsenate, $50 \mu \mathrm{M}$ )-treated, As $+1 \mathrm{mM} \mathrm{BSO}$, and As $+1 \mathrm{mM}$ BSO $+100 \mu \mathrm{M}$ NaHS treatment protocols by qRTPCR, followed by $2 \%$ agarose gel electrophoresis with ubiquitin used for cDNA normalization (a) and (b) their relative expression levels. Data are mean $\pm \mathrm{SE}$ of three biological replicates with average of three technical replicates/biological replicate. Asterisk denotes the significant changes (up- or down-regulation) in relation to control (set as 1$)$ at $P<0.05$. Lane 1 Mother control, 2 As-treated VL-63, 3 As + BSO-treated VL-63, 4 As + BSO + NaHS-treated VL-63, 5 Mutant control, 6 As-treated mutant, 7 As + BSO-treated mutant, 8 As + BSO + NaHS-treated mutant; M-100-bp DNA marker (M) (arrow $200 \mathrm{bp}$ )

$\mathrm{Cu} / \mathrm{Zn}$ SOD $I$ and $I I$ were significantly $(P \leq 0.0001)$ elevated in VL-63 but remained low in pvsodl mutant. Expressions of APX II could not be detected whereas DHAR was significantly down-regulated and change was not significant for GR and CAT expressions in VL-63. GST II repressed and GST I transcript was not expressed in both the genotypes in presence of BSO in the medium (Fig. 2a, c). In pvsodl mutant, apart from $A P X I$ and $I I$, a third isoform $A P X I I I$ expressed along with more than twofold up-regulations of CAT and DHAR transcripts over MuC (Fig. 3a, b). The APX III isoform although down-regulated during As treatment alone, was up-regulated by about 2.3and 2.7-fold over MuC in presence of BSO (Fig. 3b).

At As + BSO + NaHS, expressions of different transcripts followed more or less same trend in both the genotypes in relation to As + BSO treatment (Figs. 2, 3).

\section{Discussion}

Present common bean genotypes exhibited contrasting responses to $50 \mu \mathrm{M}$ As treatment. Shoots and roots dry masses were not affected in pvsodl mutant but shoot growth was severely inhibited in VL-63. This is despite the lower shoot: root As ratio $(<1.0)$ in VL-63 but higher $(>1.0)$ in the mutant. This apparently conflicting situation can be better explained if we take the response of both genotypes in $\mathrm{As}+\mathrm{BSO}$ and $\mathrm{As}+\mathrm{BSO}+\mathrm{NaHS}$ treatments under consideration. BSO is a specific inhibitor of GSH biosynthesis and in absence of BSO, available GSH pool can facilitate GSH-As binding, thus preventing the translocation of As from the root to shoot in VL-63. The reverse trend in accumulation pattern i.e. higher shoot to root $(>1.0)$ in VL-63 under BSO exposure was presumably due to the absence of enough GSH pool, which perturbed the sequestration of As in roots, resulting into maximum translocation of As (V) to the shoots. In this backdrop, high As accumulation and normal growth (MuC like) of the shoots indicated greater As tolerance and localized detoxification capability of the mutant compared with that found in VL-63.

Growing evidences indicate critical importance of $\mathrm{S}$ in As tolerance and detoxification, and GSH plays central role in this process (Finnegan and Chen 2012; Talukdar 2013). During its synthesis, GSH exclusively requires Cys as one of its building blocks, and thus stimulation in up-stream thiol cascade is required to keep the Cys and GSH levels as per the cellular requirements. In the pvsodl mutant, this stimulation was possible due to enhanced expressions of sulfate transporters and activity of OAS-TL, $\gamma$-ECS and PCS. Significant up-regulation of PvSultr2;1 and PvSul$\operatorname{tr} 2 ; 2$ in leaves of As-treated pvsodl mutant strongly indicated induction of sulfate transporters involved in xylem loading of sulfate and its subsequent transport from root to shoot to meet the growing $\mathrm{S}$ demand in photosynthetic organs due to overaccumulation of As. Significant increase in OAS-TL, $\gamma$-ECS and PCS activities in the mutant might 
be due to elevated expressions of OAS-TL $A$ and $B, \gamma$-ECS and PCS transcripts. Stimulation of this entire thiol cascade machinery indicated that high As-exposure necessitated greater thiol demand in tolerant genotype which is being met through coordinated induction of thiol cascade. Obviously, normal level (close to control) of Cys in As-treated pvsodl mutant is a strong indication of availability of enough thiol pools to meet the escalating consumption of downstream thiol moieties.

Proper augmentation of thiolic capacity with antioxidant defense components is essential in conferring tolerance to As stress. Enhanced GR activity due to $>$ twofold upregulation of both GRI and GRII in As-treated pvsodI mutant ensured effective recycling of GSH by preventing excess build-up of GSSG. Increased GSTs activity in the As-treated mutant was mainly due to threefold to fourfold induction of GSTI and II transcripts. GR transcript was found elevated in As-treated Indian mustard (Khan et al. 2009) while GST activity and its transcripts were upregulated in Arabidopsis, rice, lentils and Brassica subjected to As treatment (Abercrombie et al. 2008; Chakrabarty et al. 2009; Srivastava et al. 2009; Talukdar and Talukdar 2014a). Besides GR and GSTs, enhanced transcriptional expressions of APX I and II isoforms led to As-induced elevation of APX activity in the pvsodl mutant. Significant increase in SOD activity in VL-63 was orchestrated through elevated expressions of $\mathrm{Cu} / \mathrm{Zn}$ SOD I and $C u / Z n$ SOD II transcripts, indicating As-induced excess superoxide generation. The minimum SOD level in pvsodl mutant was maintained by enhanced expressions of $\mathrm{Cu} / \mathrm{Zn} S O D I$ and $M n S O D$ isoforms. The result pointed out that cytosolic isoforms $(\mathrm{Cu} / \mathrm{Zn}$ SODs) in both bean genotypes played pivotal roles in maintaining SOD activity during As-exposures, which confirmed earlier findings (Abercrombie et al. 2008; Talukdar and Talukdar 2013, 2014a). Obviously, stimulated SOD activity in the present case ensured effective dismutation of As-induced excess superoxide generation but at the same time it produced $\mathrm{H}_{2} \mathrm{O}_{2}$ as bi-product. Increased APX and GST levels, supported by DHAR and GR, have not only ensured effective scavenging of $\mathrm{H}_{2} \mathrm{O}_{2}$ and lipid peroxides but also maintained favorable AsA as well as GSH redox $(>0.8)$ in the As-treated mutant despite down-regulation of CAT. Considerable differences were found between VL-63 and $p v$ sodl mutant for GSH level even in the absence of As which might be due to their genotypic differences and might not be directly influenced by SOD activity. This fact was further substantiated by the significant increase of GSH in the mutant over VL-63 under As-exposure alone but SOD activity was consistently low in the mutant irrespective of treatment protocols. The direct effect of SOD in controlling the level of GSH in the present case thus seems unclear and needs further study. Absence of any induction in up-stream thiol metabolisms and reduction in downstream ROS-scavenging capacity led to excess $\mathrm{H}_{2} \mathrm{O}_{2}$ generation in photosynthetic organs of VL-63. This triggered elevated level of lipid peroxidation and membrane leakage, marking the onset of As-induced oxidative stress in the mother genotype.

Functional interplay between Cys metabolisms and down-steam antioxidant defense was more evidenced when BSO was co-applied with As and also with As + NaHS. The pvsodl seedlings effectively counterbalanced As-induced oxidative stress by managing $\mathrm{H}_{2} \mathrm{O}_{2}$ and lipid peroxidation level within control level in presence of BSO despite complete inhibition of $\gamma$-ECS activity, nearly fivefold decrease in GSH redox and significant downregulation of PCS transcripts. Furthermore, absence of GST $I$ and repression of GST II isoforms led to sharp decline in GST activity in As-treated mutant, indicating reduction in GSH-dependent antioxidant defense capability due to nonavailability of enough GSH pool. In this scenario, significant induction of GO transcripts suggested a strong linkage between inhibition of GSH biosynthesis and photorespiratory $\mathrm{H}_{2} \mathrm{O}_{2}$ generation capacity of the plant. Inverse relationship between GSH pool and expressions of GO transcripts was also observed in $r l f L-1$ mutant of grass pea in which diminishing GSH redox due to BSO treatment led to enhanced $\mathrm{GO}$ expressions and photorespiratory $\mathrm{H}_{2} \mathrm{O}_{2}$ production (Talukdar and Talukdar 2014b). In this backdrop, increasing AsA content coupled with enhanced activity of DHAR, APX and CAT suggested induction in AsA-mediated antioxidant defense in the pvsodl mutant as a bypass mode of GSH. Interestingly, APX III isoform was unique in the mutant which was up-regulated only when BSO was added in the medium. It is also noteworthy that apart from APX I, expressions of all the isoforms of APX, DHAR and CAT elevated markedly in this treatment compared to As treatment alone.

Remarkably enough, Cys level in the pvsodl mutant did not change significantly in relation to its $\mathrm{MuC}$, despite blockage of its channeling to GSH by BSO. Accumulated free Cys, but not GSH, has the capacity to act as a prooxidant within cell and can affect cellular redox balance (Park and Imlay 2003). Perhaps, Cys level in the present mutant was managed by inducing its degradation through desulfuration and by regulating its synthesis through OAS-TL. LCD and DCD play predominant roles in Cys desulfuration which is pivotal in Cys-degraded $\mathrm{H}_{2} \mathrm{~S}$ generation within cell (Bloem et al. 2004; Chen et al. 2011). Substantial enhancement in LCD/DCD transcripts and their activity in pvsodl mutant in presence of BSO strongly indicated metabolic diversion of Cys through its degradation, thus, preventing its build up at prooxidant level and indicating that Cys-degradation pathway is induced when its utilization to GSH synthesis is inhibited (here by BSO). Mutants 
deficient in Cys-desulfuration pathway exhibited overaccumulation of free Cys which led to excess ROS generation and oxidative imbalance (Álvarez et al. 2010; Talukdar 2014) but relieved when Cys-desulfuration was induced (Talukdar and Talukdar 2014b). $\mathrm{H}_{2} \mathrm{~S}$ treatment has been implicated in inducing GSH-mediated plant stress tolerance (Calderwood and Kopriva 2014) but it is not known whether GSH is the sole receiver of the $\mathrm{H}_{2} \mathrm{~S}$ effects. Cys desulfuration in the present As + BSO- and As + $\mathrm{BSO}+\mathrm{NaHS}-$ treated pvsodl mutant was accompanied with the huge accumulation of endogenous $\mathrm{H}_{2} \mathrm{~S}$ and stimulation of AsAdependent antioxidant defense. High $\mathrm{H}_{2} \mathrm{~S}$ has the capacity to regulate OAS-TL activity through Cys-synthase complex, triggering association of complex and decrease in OAS-TL activity (Hell and Wirtz 2011). In the pvsodl mutant, OAS-TL activity was regulated by counterbalancing up-regulation of OAS-TLA with down-regulation of its $O A S-T L B$ isoform in presence of BSO. The result strongly confirmed metabolic diversion of Cys to $\mathrm{H}_{2} \mathrm{~S}$ through induction of desulfuration pathway. Obviously, along with induced desulfuration, the up-stream regulation of Cys synthesis was necessitated to prevent excess build-up of free Cys in view of a blockage of its downstream channeling to GSH. It is thus apparent that fates of up-stream thiol status depend on functional interplay between downstream thiol-components, preferably between $\mathrm{GSH}$ and $\mathrm{H}_{2} \mathrm{~S}$ both of which require Cys to be built-up. This huge rise in $\mathrm{H}_{2} \mathrm{~S}$ level in the pvsodl mutant could be compared as ' $\mathrm{H}_{2} \mathrm{~S}$ burst', which coupled with significant enhancement of APX, DHAR and CAT activity and decline in GO level resulted in significant reduction in ROS-induced oxidative damage in the mutant. Certainly, GSH is not the sole receiver of $\mathrm{H}_{2} \mathrm{~S}$ effects. In the present study, $\mathrm{H}_{2} \mathrm{~S}$ seems to play dual roles; maintained and stabled Cys level and induced AsA-dependent antioxidant defense in pvsodl mutant against Astoxicity as an alternate mode of GSH-dependent defense. In agreement with the present findings, BSO-treated rlfL- 1 mutant of Lathyrus induced Cys desulfuration which played prominent roles in reversal of cell proliferations and restoration of normal mitosis during low GSH level (Talukdar and Talukdar 2014b). GSH synthesis was also blocked in VL-63 but there was no induction in $\mathrm{H}_{2} \mathrm{~S}$ production in the genotype. This possibly led to lowering of AsA redox and AsA-dependent antioxidant defense under As-exposure. Obviously, low $\mathrm{H}_{2} \mathrm{~S}$ level in the mother genotype could not functionally compensate the loss of GSH pool in the combined presence of As and BSO.

\section{Conclusions}

Present study revealed functional interplay between Cysgenerated $\mathrm{H}_{2} \mathrm{~S}$ at up-stream and GSH-dependent antioxidant defense in downstream thiol metabolisms in presence of As (V). Results indicated onset of As-induced oxidative stress in VL-63 due to lack of responsiveness of its entire thiol cascade. Contrastingly, pvsodl mutant exhibited As tolerance even when BSO was co-applied with As. The mutant induced Cys-degradation pathway to generate huge endogenous $\mathrm{H}_{2} \mathrm{~S}$ which stimulated AsA-mediated antioxidant defense and regulated Cys synthesis via OAS-TL in the background of low GSH redox and effectively prevented As-induced oxidative stress. The study pointed out that $\mathrm{H}_{2} \mathrm{~S}$ holds the key in cellular Cys homeostasis and modulation of antioxidant defense against Astoxicity. Also, a metabolic diversion is imminent when Cys-consumption route towards GSH is blocked and GSH may not be the sole receiver of endogenous $\mathrm{H}_{2} \mathrm{~S}$-mediated cellular signaling during As tolerance of plants.

Acknowledgments Author is grateful to Dr. Tulika Talukdar and three anonymous reviewers for critically reviewing the manuscript.

Conflict of interest No conflict of interest is involved in any way with the present work.

Open Access This article is distributed under the terms of the Creative Commons Attribution License which permits any use, distribution, and reproduction in any medium, provided the original author(s) and the source are credited.

\section{References}

Abercrombie JM, Halfhill MD, Ranjan P, Rao MR, Saxton AM, Yuan JS, Stewart CN Jr (2008) Transcriptional responses of Arabidopsis thaliana plants to $\mathrm{As}(\mathrm{V})$ stress. BMC Plant Biol 8:87-96

Álvarez C, Calo L, Romero LC, Garcia I, Gotor C (2010) An O-acetylserine (thiol)lyase homolog with L-cysteine desulfhydrase activity regulates cysteine homeostasis in Arabidopsis. Plant Physiol 152:656-669

Baker AL, Tolbert NE (1966) Glycolate oxidase (ferredoxin-containing form). Methods Enzymol 9:338-342

Beyer WF, Fridovich I (1987) Assaying for superoxide dismutase activity: some large consequences of minor changes in conditions. Anal Biochem 161:559-566

Bhattacharya P, Samal AC, Majumdar J, Santra SC (2010) Arsenic contamination in rice, wheat, pulses, and vegetables: a study in an arsenic affected area of West Bengal, India. Water Air Soil Pollut 213:3-13

Bloem E, Riemenschneider A, Volker J, Papenbrock J, Schmidt A, Salac I, Haneklaus S, Schnug E (2004) Sulphur supply and infection with Pyrenopeziza brassicae influence L-cysteine desulphydrase activity in Brassica napus L. J Exp Bot 55:2305-2312

Bradford MM (1976) A rapid and sensitive method for quantification of microgram quantities of protein utilizing the principle of protein-dye binding. Ann Biochem 72:248-254

Calderwood A, Kopriva S (2014) Hydrogen sulfide in plants: from dissipation of excess sulfur to signaling molecule. Nitric Oxide. doi:10.1016/j.niox.2014.02.005

Carlberg I, Mannervik B (1985) Glutathione reductase. In: Alton M (ed) Methods in enzymology. Academic, San Diego, pp 484-490 
Chakrabarty D, Trivedi PK, Misra P, Tiwari M, Shri M, Shukla D et al (2009) Comparative transcriptome analysis of arsenate and arsenite stresses in rice seedlings. Chemosphere 74:688-702

Chen J, Wu FH, Wang WH, Zheng CJ, Lin GH, Dong XJ, He JX, Pei ZM, Zheng HL (2011) Hydrogen sulphide enhances photosynthesis through promoting chloroplast biogenesis, photosynthetic enzyme expression, and thiol redox modification in Spinacia oleracea seedlings. J Exp Bot 62:4481-4493

Dionisio-Sese M, Tobita S (1998) Antioxidant responses of rice seedlings to salinity stress. Plant Sci 135:1-9

Finnegan PM, Chen W (2012) Arsenic toxicity: the effects on plant metabolism. Front Physio 3:182

Gaitonde MK (1967) A spectrophotometric method for the direct determination of cysteine in the presence of other naturally occurring amino acids. Biochem J 104:627-633

Griffith OW (1980) Determination of glutathione and glutathione disulfide using glutathione reductase and 2-vinylpyridine. Anal Biochem 106:207-212

Gupta DK, Tripathi RD, Mishra S, Srivastava S, Dwivedi S, Rai UN, Yang XE, Huanj H, Inouhe M (2008) Arsenic accumulation in root and shoot vis-a-vis its effects on growth and level of phytochelatins in seedlings of Cicer arietinum L. J Environ Biol 29:281-286

Hell R, Wirtz M (2011) Molecular biology, biochemistry and cellular physiology of cysteine metabolism in Arabidopsis thaliana. Arabidopsis Book 9:e0154

Hodges DM, Delong JM, Forney CF, Prange RK (1999) Improving the thiobarbituric acid-reactive substances assay for estimating lipid peroxidation in plant tissues containing anthocyanin and other interfering compounds. Planta 207:604-611

Howden R, Goldsbrough PB, Andersen CR, Cobbett CS (1995) Cadmium sensitive, cad1 mutants of Arabidopsis thaliana are phytochelatin deficient. Plant Physiol 107:1059-1066

Khan I, Ahmad A, Iqbal M (2009) Modulation of antioxidant defence system for arsenic detoxification in Indian mustard. Ecotoxico Environ Saf 72:626-634

Kopriva S, Mugford SG, Baraniecka P, Lee BR, Matthewman CA, Koprivova A (2012) Control of sulfur partitioning between primary and secondary metabolism in Arabidopsis. Front Plant Sci 3:1-9

Law MY, Charles SA, Halliwell B (1983) Glutathione and ascorbic acid in spinach (Spinacia oleracea) chloroplast. The effect of hydrogen peroxide and paraquat. Biochem J 10:899-903

Li Z-S, Zhen R-G, Rea PA (1995) 1-chloro-2,4-dinitrobenzeneelicited increase in vacuolar glutathione- $S$-conjugate transport activity. Plant Physiol 109:177-185

Liao D, Pajak A, Karcz SR, Chapman BP, Sharpe AG, Austin RS, Datla R, Dhaubhade S, Marsolais F (2012) Transcripts of sulphur metabolic genes are co-ordinately regulated in developing seeds of common bean lacking phaseolin and major lectins. J Exp Bot 63:6283-6295

Livak KJ, Schmittgen TD (2001) Analysis of relative gene expression data using real-time quantitative PCR and the $2^{-\Delta \Delta \mathrm{ct}}$ method. Methods 25:402-408

Nakano Y, Asada K (1981) Hydrogen peroxide is scavenged by ascorbate specific peroxidase in spinach chloroplast. Plant Cell Physiol 22:867-880
Noctor G, Mhamdi A, Chaouch S et al (2012) Glutathione in plants: an integrated overview. Plant Cell Environ 35:454-484

Park S, Imlay JA (2003) High levels of intracellular cysteine promote oxidative DNA damage by driving the Fenton reaction. J Bacteriol 185:1942-1950

Riemenschneider A, Wegele R, Schmidt A, Papenbrock J (2005) Isolation and characterization of a D-cysteine desulfhydrase protein from Arabidopsis thaliana. FEBS J 272:1291-1304

Saito K, Kurosawa M, Tatsuguchi K, Takagi Y, Murakoshi I (1994) Modulation of cysteine biosynthesis in chloroplasts of transgenic tobacco overexpressing cysteine synthase [O-acetylserine(thiol)lyase]. Plant Physiol 106:887-895

Seelig GF, Meister A (1984) $\gamma$-Glutamylcysteine synthetase: interactions of an essential sulfhydryl group. J Biol Chem 259:3534-3538

Sekiya J, Schmidt A, Wilson LG, Filner P (1982) Emission of hydrogen sulfide by leaf tissue in response to L-cysteine. Plant Physiol 70:430-436

Srivastava S, Srivastava AK, Suprasanna P, D’Souza SF (2009) Comparative biochemical and transcriptional profiling of two contrasting varieties of Brassica juncea $\mathrm{L}$. in response to arsenic exposure reveals mechanisms of stress perception and tolerance. J Exp Bot 60:3419-3431

Stoeva N, Berova M, Zlatev Z (2005) Effect of arsenic on some physiological parameters in bean plants. Biol Plant 49:293-296

Takahashi H, Kopriva S, Giordano M, Saito K, Hell R (2011) Sulfur assimilation in photosynthetic organisms: molecular functions and regulations of transporters and assimilatory enzymes. Annu Rev Plant Biol 62:157-184

Talukdar D (2013) Arsenic-induced oxidative stress in the common bean legume, Phaseolus vulgaris L. seedlings and its amelioration by exogenous nitric oxide. Physiol Mol Biol Plants 19:69-79

Talukdar D (2014) A common bean (Phaseolus vulgaris) mutant with constitutively low cysteine desulfhydrase activity exhibits growth inhibition but uniquely shows tolerance to arsenate stress. Env Exp Biol 12:73-81

Talukdar D, Talukdar T (2013) Superoxide-dismutase deficient mutants in common beans (Phaseolus vulgaris L.): genetic control, differential expressions of isozymes, and sensitivity to arsenic. BioMed Res Int 2013: Article ID 782450, p 11. doi:10. 1155/2013/782450

Talukdar D, Talukdar T (2014a) Coordinated response of sulfate transport, cysteine biosynthesis and glutathione-mediated antioxidant defense in lentil (Lens culinaris Medik.) genotypes exposed to arsenic. Protoplasma 251:839-855

Talukdar D, Talukdar T (2014b) Leaf rolling and stem fasciation in grass pea (Lathyrus sativus L.) mutant are mediated through glutathione-dependent cellular and metabolic changes and associated with a metabolic diversion through cysteine during phenotypic reversal. BioMed Res Int 2014: Article ID 479180, p 21. doi: $10.1155 / 2014 / 479180$

Wang CQ, Chen M, Wang BS (2007) Betacyanin accumulation in the leaves of C3 halophyte Suaeda salsa L. is induced by watering roots with $\mathrm{H}_{2} \mathrm{O}_{2}$. Plant Sci 172:1-7 